\title{
Optical properties of textile materials added with UV protective biomaterials
}

\author{
A. Dominguez-Pacheco ${ }^{1}$ (D) B. Gomez-Uzeta ${ }^{1}$ - C. Hernandez-Aguilar ${ }^{1}$ (I) $\cdot$ A. Cruz-Orea ${ }^{2}$ (I) $\cdot$ V. Cruz-San Martín ${ }^{3}$
}

Received: 28 September 2019 / Accepted: 9 December 2019 / Published online: 16 December 2019

(c) Springer Nature Switzerland AG 2019

\begin{abstract}
Scientific reports around the world indicate that solar radiation has increased its intensity and consequently its UV radiation, making it necessary to improve protective materials against this radiation. Textiles can be used as a protective material against the UV radiation, and one way to increase their UV protection capacity could be by adding biomaterials with optical absorption in the UV region. In the present study, flavonoids, natural pigments absorbing UV radiation, were extracted from corn seeds by using two methods (maceration and microwave oven assisted). The extracted flavonoids as well as a commercial protector of UV-B radiation were added to a cotton textile and then exposed to different UV-B radiation times ( $0 \mathrm{~min}, 30 \mathrm{~min}$ and $60 \mathrm{~min}$ ). The optical absorption spectra of flavonoids and textile materials were obtained by photoacoustic spectroscopy. These spectra showed differences, observing that the textile added with commercial protector was degraded with the exposition of UV radiation; meanwhile in the case of the textile added with flavonoids increased its UV protection.
\end{abstract}

Keywords Photoacoustic spectroscopy · UV-B radiation · UV protection · Textiles

\section{Introduction}

Currently, technological developments seek to improve the properties of materials [1-4], with incorporation of other materials or biomaterials through different methods to increase their properties and make them more absorbent, resistant, flexible, etc., to be able to respond to the new environmental conditions of temperature, radiation and humidity, among others [5-7]. One of the problems with more repercussions is the increase in UV radiation. There are reports that the UV light radiation on several regions of the planet has varied $7 \%$ and $35 \%$ in summer and winter, respectively [8]. In the UV-B radiation, ranging from 280 to $315 \mathrm{~nm}$ wavelength, it has been found an aggressive impact in biological materials exposed to this radiation. In the case of humans, it has manifested as damage to DNA and RNA. Also, several investigations have been observed that visual problems are related to UV-B radiation $[9,10]$, as well as epidermal tissue, when exposed to this type of radiation with its high energy content, modify the DNA with serious damages, causing skin cancer [11]. In some countries, the skin damage cases have increased, which has led to preventive measures being taken to reduce damage in the population [12]. Developing materials for the protection of human body from harmful agents has led to the generation of several functional textiles for UV protection, antimicrobial, humidity, temperature, etc. [13-16]. Textiles are materials that allow the addition of substances and biomaterials to improve the protection against UV radiation. By other hand, it is desirable to have techniques to characterize the improved textiles, where the samples to be analyzed are not be altered

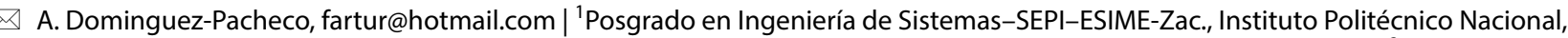
Av. Instituto Politécnico Nacional, s/n col. Lindavista, Alcaldía Gustavo A. Madero, C. P. 07730 Ciudad de México, Mexico. ${ }^{2}$ Departamento de Física, CINVESTAV-IPN, A. P. 14-740, 07360 Ciudad de México, Mexico. ${ }^{3}$ Bristol Centre for Functional Nanomaterials, School of Physics, University of Bristol, Bristol, UK. 
or destroyed. In this sense, photothermal (PT) techniques allow the optical and thermal characterization of several materials, substances or compounds [17-21] to obtain some physical parameters, such as the optical absorption coefficient, thermal effusivity, diffusivity, thermal images, heat capacity, etc. Among the PT techniques, stand out, the photoacoustic spectroscopy (PAS), which has been used to characterize optically solid materials, homogeneous liquids and biological materials to obtain their optical absorption spectra. The considerations of the mathematical model proposed by Rosencwaig and Gersho [22] have allowed the obtaining of optical absorption coefficients and thermal properties in diverse types of materials. In this study, natural pigments, extracted from corn seeds, were added to textiles to improve their protection capacity against UV radiation. PAS was used to obtain the optical absorption spectra of natural pigments, extracted from corn seeds and textiles added with these pigments.

\section{Materials and methods}

\subsection{Materials}

The natural pigments used in this study were extracted from the cooking of commercial white corn kernels, BD-57 variety, produced in Morelos State, Mexico. It is worth mentioning when cooking different agricultural grains, several substances contained in superficial layers or skin are released; most of them are phenols and flavonoids [23-25]. For the cooking of corn kernels, $2 \%$ of $\mathrm{Ca}(\mathrm{OH})_{2}$ was incorporated into boiling water with the kernels during $30 \mathrm{~min}$. The extraction of the natural pigments, from the obtained samples, was done by two methods, maceration and microwave oven assisted. Finally, the obtained powder was placed in a solution methanol/water (60/40) to measure the weight transfer in components in both extraction methods of these liquid solutions. The photoacoustic spectra of the powder samples were obtained by PAS.

\subsection{Addition of UV protectors and exposure to UV radiation}

The obtained natural pigments from maize seeds by maceration method and commercial chemical anti-UV agent were added to samples of cotton textiles by the preparation and fixation method. The natural pigments obtained by maceration method were chosen due to their high content of phenols and flavonoids, when compared with the pigment contents extracted from the microwave-assisted method. Subsequently, the samples were placed inside a UV-B radiation camera with an emission range between
290 and $315 \mathrm{~nm}$, with power of $2.5 \mathrm{~W}$, and a distance of $15 \mathrm{~cm}$ between the lamp and the samples. After samples were exposed to 10,30 and $60 \mathrm{~h}$, and their photoacoustic spectra were obtained.

\subsection{PAS experimental setup}

Figure 1a shows the PAS experimental setup consisting of a xenon lamp, as a source of excitation light, a monochromator to obtain a monochromatic light beam at different wavelengths, a mechanical chopper, to obtain a modulated light beam at constant frequency of $17 \mathrm{~Hz}$, and an optical fiber for guiding the light beam into the photoacoustic (PA) cell, which is hermetically sealed, where the sample is contained. The generated PA signal, within the PA cell, is detected by an electret microphone connected to a lock-in amplifier, which processes the PA signal being sent to a computer to record the photoacoustic signals, amplitude and phase, as a function of the incident wavelength. The sample PA spectra were obtained as a function of the incident wavelength, ranging from 250 to $500 \mathrm{~nm}$. These spectra were analyzed to study these natural pigments, in their liquid form, and also, the textile materials without and after addition of the bio-protective material against UV radiation.

\section{Results}

Figure $1 \mathrm{~b}$ shows the PA spectra obtained from the solution of the corn grain residues when performing the extraction by both methods. It is possible to observe differences in the PA signal, which could be due to the fact that the maceration extraction is performed without energy that excites the solution, while in the microwave-assisted method the solution is excited by a radiant energy. In both extraction methods, the PA signal has a similar behavior, but the microwave-assisted method has a lower intensity level, indicating that the absorption of the sample decreases when compared with the maceration method. The extracted solutions by the two methods have an optical absorption band ranging from 260 to $400 \mathrm{~nm}$, being this absorption band characteristic of solutions with extracts of phenolic acids and flavonoids, reported in the literature by different characterization techniques [26-28].

Figure 2 shows the PA spectra of the cotton textiles, (a) added with the anti-UV commercial protector and (b) added with the extracted solution (phenols and flavonoids) of the corn grains; also, the first derivative can be observed in the inset of both figures to observe better the wavelength of the maximum absorption peaks of the samples. In Fig. 2a, is observed that commercial protector anti-UV-B, when it is exposed to 30 and $60 \mathrm{~h}$, due 

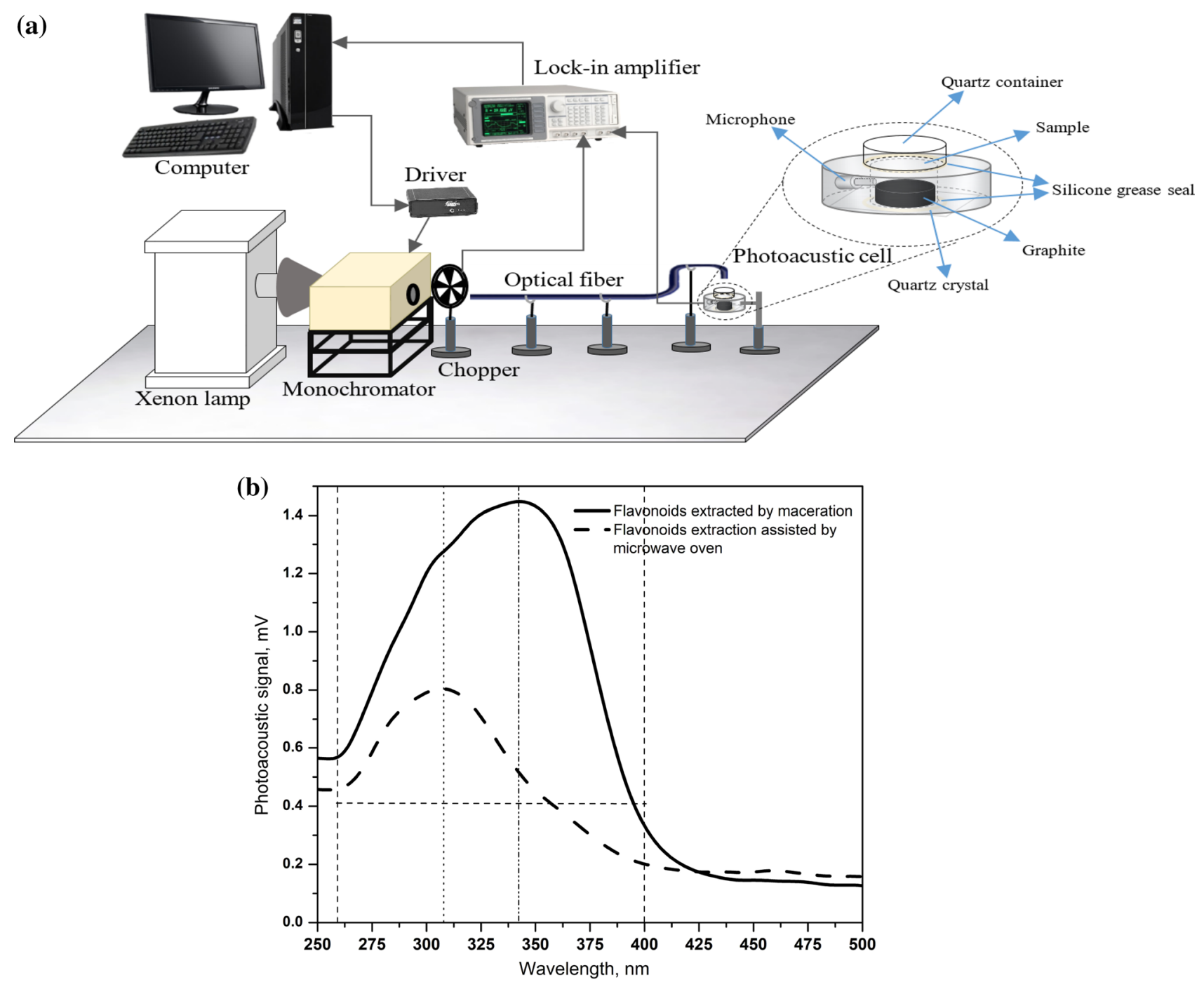

Fig. 1 a PAS experimental setup and $\mathbf{b}$ photoacoustic spectra. Flavonoid extracts by different methods

to the UV-B radiation it begins to degrade minimally at $30 \mathrm{~h}$ with respect to the sample without exposure, but degradation increases at $60 \mathrm{~h}$. This degradation being more noticeable in the range of 350 to $500 \mathrm{~nm}$. On the other hand, in Fig. $2 \mathrm{~b}$ we can observe the photoacoustic spectra of the cotton textiles added with the solution extracted from the corn grains, showing that it increases the absorption throughout the range measured from 250 to $400 \mathrm{~nm}$. After $400 \mathrm{~nm}$, the absorption remains similar, even when the sample was exposed to 30 and $60 \mathrm{~h}$ of UV-B radiation, having a greater increase in the maximum absorbent peak at $300 \mathrm{~nm}$. Observing the differences shown between the photoacoustic spectra in Fig. 2a, b in both cases, the optical absorption coefficients and the penetration length of the samples were calculated to compare textiles without radiation and those exposed to radiation of 30 and $60 \mathrm{~h}$.

\subsection{Calculation of optical absorption coefficient and optical penetration length}

The optical absorption coefficient $(\beta)$ and the optical penetration length $\left(I_{\beta}\right)$ of the textiles were determined from the equation of Poulet et al. [29]. It is possible to observe in Eq. (1) that $\beta$ is a function of the normalized PA signal amplitude $(q)$ obtained by PAS.

$\beta=\frac{q}{\mu_{s}} \frac{q+\sqrt{2-q^{2}}}{1-q^{2}}$

In Eq. (1), the normalized PA signal amplitude (q) was obtained by the ratio of the sample PA signal amplitude to the charcoal powder PA signal amplitude, in order to take into account the Xe lamp emission spectrum. After verification of the textile thermal thickness condition: $I_{s} / \mu_{s} \gg 1$, 

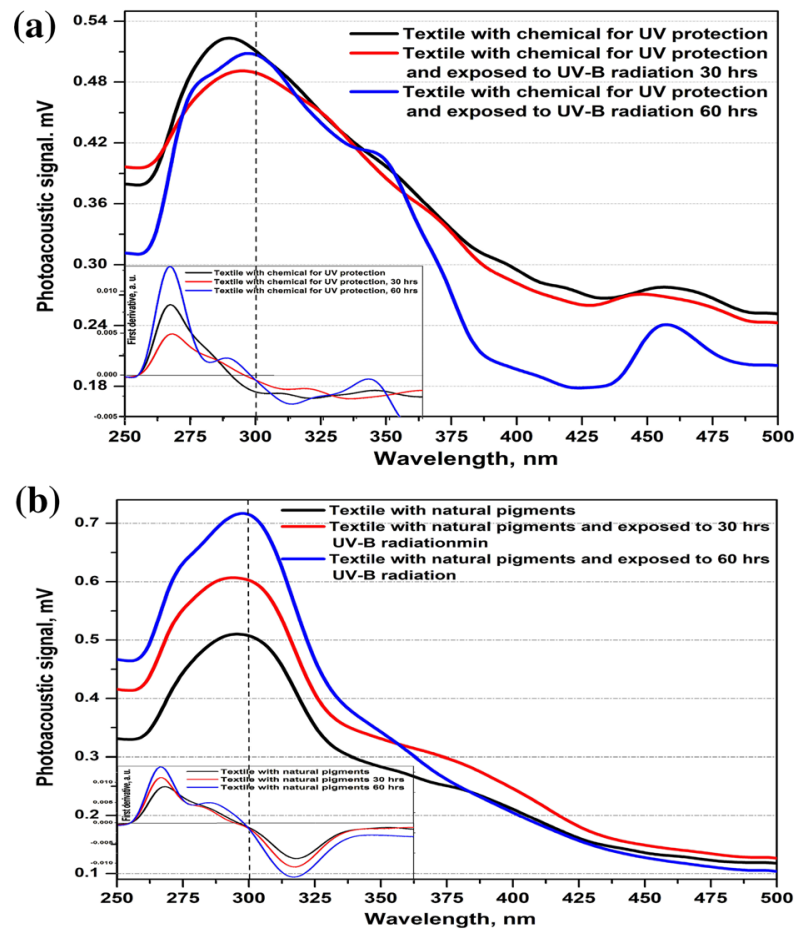
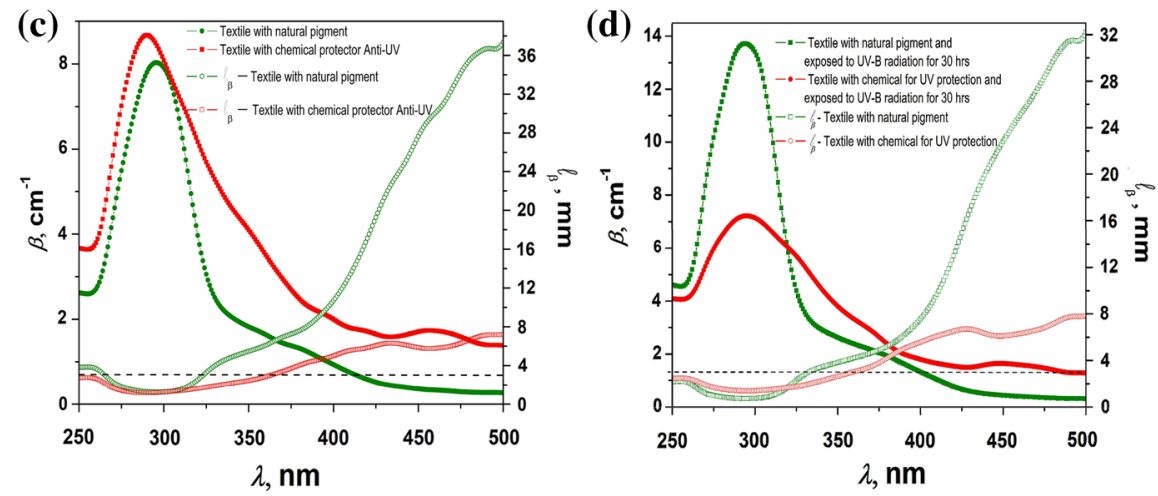

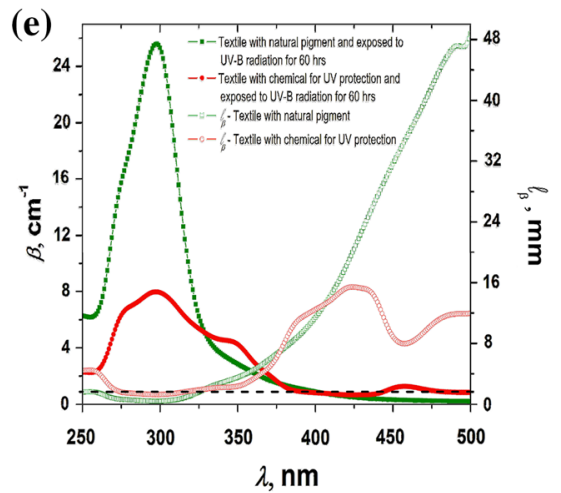

Fig. 2 Photoacoustic spectra of textiles added with a commercial UV protector and $\mathbf{b}$ waste solution of corn kernels, differences between optical absorption coefficients and penetration length in textiles with commercial UV protector and natural pigments $\mathrm{c}$ without radiation exposure, $\mathbf{d}$ radiation exposed $30 \mathrm{~h}$ and $\mathbf{e} 60 \mathrm{~h}$

optical absorption coefficient, when compared with the textile added with natural pigments (extracted from the corn kernels), and a wider band in the optical penetration length, in a range between $250 \mathrm{~nm}$ and $375 \mathrm{~nm}$, which indicates that this sample, in the mentioned range, shows greater opacity and less penetration of UV light. In the case of the textiles added with chemical UV protection and natural pigments exposed to UV-B radiation during $30 \mathrm{~h}$ and $60 \mathrm{~h}$, their optical absorption spectra are shown in Fig. $2 \mathrm{~d}$, e, respectively. It is possible to observe from Fig. $2 \mathrm{~d}$ that the textile with chemical UV protection preserves its optical absorption and penetration length as before of radiation, as shown in Fig. $2 \mathrm{c}$ for this textile, while the textile with natural pigments increases its absorption and optical penetration properties. The 
penetration length is similar to the UV chemical protector, ranging from 250 to $360 \mathrm{~nm}$. On the one hand, from Fig. 2c, it can be observed that the textile with UV chemical protector begins to degrade its optical absorption, but optical penetration remains in the same range. On the other hand, the textile with natural pigments increases its optical absorption and penetration properties, showing an optical penetration length, in the range from 250 to $370 \mathrm{~nm}$, close to the UV protector, being opaque both materials added to the textiles, not allowing the penetration of UV light in this region.

\section{Conclusion}

By means of PAS, it is possible to determine the differences that exist in extracted solutions of natural pigments obtained by means of different methods, as well as the effects of degradation produced by UV-B radiation in textile materials added with commercial protector or natural pigments, extracted from corn kernels. These pigments could be used as a protector for UV-B radiation by adding in natural textiles.

Acknowledgements The authors would like to thank the Instituto Politécnico Nacional, through the CONACYT, COFAA, EDI and the support Research and Postgraduate Secretariat (Project SIP 20195955) and also, Photothermal Techniques Laboratory of Physics Department, CINVESTAV-IPN for the support to develop the experiments of the present study. We also thank Ing. Esther Ayala for her technical support at the Physics Department, CINVESTAV-IPN.

\section{Compliance with ethical standards}

Conflict of interest On behalf of all authors, the corresponding author states that there is no conflict of interest.

\section{References}

1. Davidovits J (1991) Geopolymers: inorganic polymeric new materials. J Therm Anal Calorim 37:1633-1656

2. Nakata K, Ochiai T, Murakami T, Fujishima A (2012) Photoenergy conversion with $\mathrm{TiO}_{2}$ photocatalysis: new materials and recent applications. Electrochim Acta 84:103-111

3. LiW, Liu J, Zhao D (2016) Mesoporous materials for energy conversion and storage devices. Nat Rev Mater 1:16023

4. Berglund LA, Burgert I (2018) Bioinspired wood nanotechnology for functional materials. Adv Mater 30:1704285

5. Galafassi D, Kagan S, Milkoreit M et al (2018) Raising the temperature: the arts on a warming planet. Curr Opin Environ Sust 31:71-79

6. Kozakis T, Kaltenegger L, Hoard DW (2018) UV surface environments and atmospheres of earth-like planets orbiting white Dwarfs. Astrophys J 862:69

7. Gómez-Leal I, Kaltenegger L, Lucarini V, Lunkeit F (2019) Climate sensitivity to ozone and its relevance on the habitability of Earthlike planets. Icarus 321:608-618

8. Kerr JB, McElroy CT (1993) Evidence for large upward trends of ultraviolet-B radiation linked to ozone depletion. Science 262:032-1034

9. Schlötzer-Schrehardt U, Hammer CM, Krysta AW et al (2012) LOXL1 deficiency in the lamina cribrosa as candidate susceptibility factor for a pseudoexfoliation-specific risk of glaucoma. Ophthalmology 119:1832-1843

10. Gribbin J (1992) El agujero del cielo. La amenaza humana a la capa de ozono. Madrid, Alianza Editorial, 232p. Documents d'anàlisi geogràtica 23:170-17

11. Biniek K, Levi K, Dauskardt RH (2012) Solar UV radiation reduces the barrier function of human skin. In: Proceedings of the National Academy of Sciences 201206851

12. World Health Organization (WHO), International Commission on Non-lonizing Radiation Protection (1995) Global solar UV index: a practical guide. WHO, Geneva

13. Mahltig B, Haufe $\mathrm{H}$, Böttcher $\mathrm{H}$ (2005) Functionalisation of textiles by inorganic sol-gel coatings. J Mater Chem 15:4385-4398

14. Dhende VP, Samanta S, Jones DM, Hardin IR, Locklin J (2011) One-step photochemical synthesis of permanent, nonleaching, ultrathin antimicrobial coatings for textiles and plastics. ACS Appl Mater Interfaces 3:2830-2837

15. Suzuki T, Wang X (2010) Nanoparticle coatings for UV protective textiles. Res J Text Apparel 14:9-20

16. Xin JH, Daoud WA, Kong YY (2004) A new approach to UV-blocking treatment for cotton fabrics. Text Res J 74:97-100

17. Rosencwaig A (1973) Photoacoustic spectroscopy of biological materials. Science 181:657-658

18. Buschmann C, Prehn H, Lichtenthaler H (1984) Photoacoustic spectroscopy (PAS) and its application in photosynthesis research. Photosynth Res 5:29-46

19. Chirtoc M, Mihilescu G (1989) Theory of the photopyroelectric method for investigation of optical and thermal materials properties. Phys Rev B 40:9606

20. Bićanić D (1991) Photoacoustic and photothermal phenomena III. Springer series in optical sciences, vol. 69. Springer, Berlin

21. Hernandez-Aguilar C, Dominguez-Pacheco A, Cruz-Orea $A$, Ivanov R (2019) Photoacoustic spectroscopy in the optical characterization of foodstuff: a review. J Spectrosc 2019:34. https://doi. org/10.1155/2019/5920948

22. Rosencwaig A, Gersho A (1976) Theory of the photoacoustic effect with solids. J Appl Phys 47:64-69

23. Inglett GE, Chen D (2011) Contents of phenolics and flavonoids and antioxidant activities in skin, pulp, and seeds of miracle fruit. J Food Sci 76:C479-C482

24. Singh B, Singh JP, Kaur A, Singh N (2017) Phenolic composition and antioxidant potential of grain legume seeds: a review. Food Res Int 101:1-16

25. Malenčić D, Popović M, Miladinović J (2007) Phenolic content and antioxidant properties of soybean seeds (Glycine max (L.) Merr.). Molecules 12:576-581

26. Weber G, Konieczyński P (2003) Speciation of Mg, Mn and Zn in extracts of medicinal plants. Anal Bioanal Chem 375:1067-1073

27. Stalikas CD (2007) Extraction, separation, and detection methods for phenolic acids and flavonoids. J Sep Sci 30:3268-3295

28. Chen HJ, Inbaraj BS, Chen BH (2012) Determination of phenolic acids and flavonoids in Taraxacum formosanum Kitam by liquid chromatography-tandem mass spectrometry coupled with a postcolumn derivatization technique. Int J Mol Sci 13:260-285

29. Poulet P, Chambron J, Unterreiner R (1980) Quantitative photoacoustic spectroscopy applied to thermally thick samples. J Appl Phys 51:1738-1742

30. Romeli D, Barigozzi G, Esposito S, Rosace G, Salesi G (2013) High sensitivity measurements of thermal properties of textile fabrics. Polym Test 32:1029-1036

Publisher's Note Springer Nature remains neutral with regard to jurisdictional claims in published maps and institutional affiliations. 